\title{
Echocardiographic features in spontaneous disruption of implanted tissue aortic valves
}

\author{
J M MCCOMB, N P S CAMPBELL, C M HANNA, J CLELAND \\ From the Regional Medical Cardiology Centre and the Cardiac Surgical Unit, Royal Victoria Hospital, Belfast
}

SUMMARY The echocardiographic features were recorded in three patients with spontaneous disruption of implanted tissue aortic valves. Two of the patients had xenografts, and one had a homograft. Aortic regurgitation had developed in all three spontaneously in the absence of active infective endocarditis. In each case there was severe disruption of the valve. Similar echocardiographic features have been found, usually in association with infective endocarditis or with myxomatous degeneration of the aortic valve. They have not previously been reported in association with implanted tissue aortic valves.

Specific $M$ mode echocardiographic features are thought to be typical of a ruptured or flail aortic valve. ${ }^{1}$ These features have most often been reported in association with active infective endocarditis. ${ }^{2-10}$ They have also been found in patients with a floppy or myxomatous aortic valve. ${ }^{611-15}$

We report three patients, two with aortic xenografts and one with a homograft, in whom the typical echocardiographic appearances of a ruptured aortic valve were recorded. In none was the aetiology active infective endocarditis. These features have not previously been associated with implanted tissue valves.

\section{Patients and methods}

$M$ mode echocardiography was performed in the three patients using an Ekoline 20 instrument and cross sectional echocardiography using a Varian 3000 phased array ultrasound.

\section{CASE REPORTS}

Case 1

At the age of 15 in 1977 this man had his aortic valve replaced with a glutaraldehyde fixed CarpentierEdwards xenograft, after which he was reviewed annually. There was no clinical evidence of aortic incompetence until February 1981, when at routine review an early diastolic murmur was heard for the first time. He was asymptomatic despite clinically severe aortic incompetence.

Requests for reprints to Dr N P S Campbell, Regional Medical Cardiology Centre, Royal Victoria Hospital, Belfast BT12 6BA.

Accepted for publication 18 October 1983
M mode echocardiography showed dilatation of the left ventricle. There was fluttering of both leaflets of the mitral valve, which closed at the normal time. There were fine vibrating echoes in the aortic root, both in systole and diastole, with similar vibrating echoes in the left ventricular outflow tract in diastole (Fig. 1a). Cross sectional echocardiography showed prolapse of the cusp in the non-coronary position into the left ventricular outflow tract (Fig. 1b).

Aortic valve replacement was undertaken in March 1981, without previous angiography. At operation there was a notable loss of tissue from all three cusps of the porcine aortic valve, with calcification of two. There was a tear in one of the cusps, a small piece of which was hanging free.

\section{Case 2}

A 33 year old man had an aortic valve replacement with a fresh homograft in July 1971 . In October 1971 an early diastolic murmur was first noted. Electrocardiographic evidence of left ventricular hypertrophy developed over the succeeding years. In 1981 he had clinical evidence of severe aortic incompetence. He was asymptomatic.

M mode echocardiography in February 1981 showed that the left ventricle was normal in size. There was fluttering of the anterior leaflet of the mitral valve and of the septum. There were fine fluttering echoes in diastole in the aortic root (Fig. 2).

At operation in April 1981 the homograft was found to have a hole in the cusp in the right coronary position causing severe regurgitation. There was some retraction of the other two cusps. There was no histological evidence of inflammation or of endocarditis. 

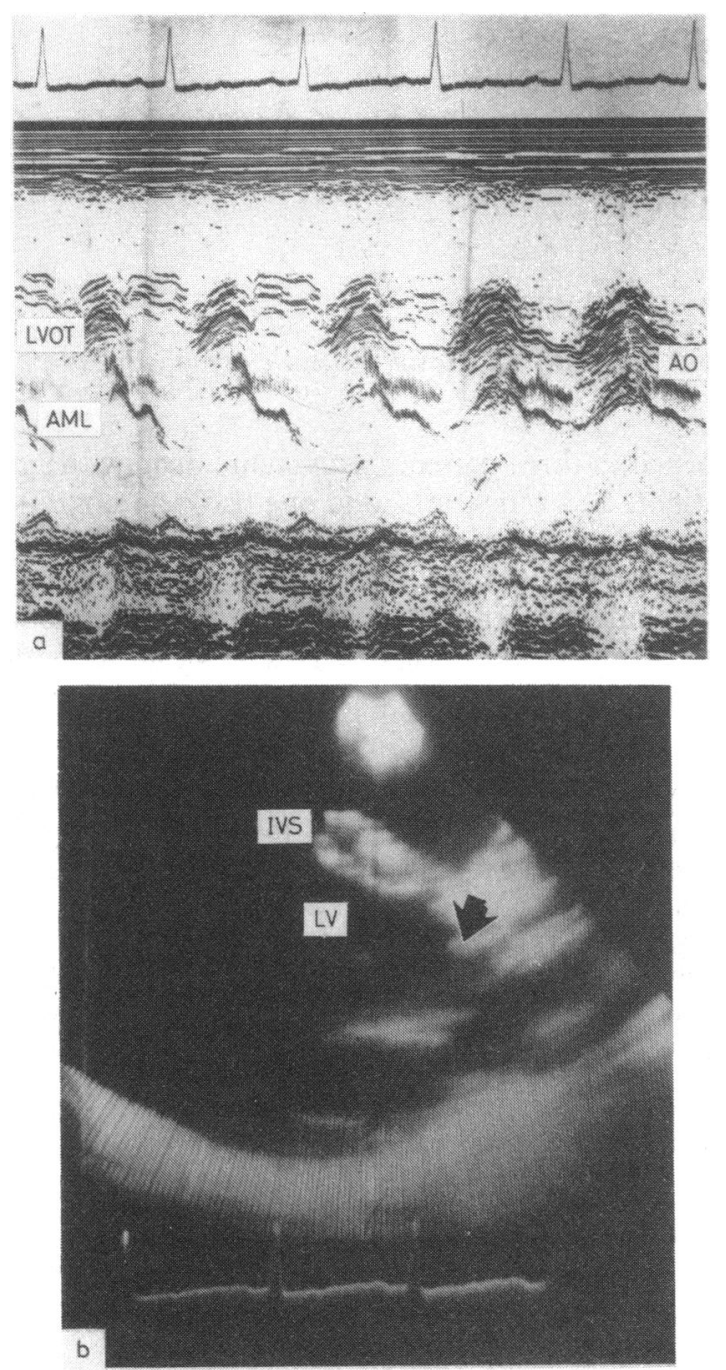

Fig. 1 (a) M mode echocardiographic scan from the left ventricular outflow tract (LVOT) to the aorta (AO) showing fluttering diastolic echoes (case 1). AML, anterior mitral leaflet. (b) Cross sectional echocardiogram (long axis parastermal view) showing diastolic prolapse of the non-coronary cusp of the aortic valve (arrowed) (case I). LV, left ventricle; IVS, interventricular septum.

\section{Case 3}

A 35 year old woman, with a history of rheumatic fever, had an aortic valve replacement with a glutaraldehyde fixed Hancock xenograft in 1975. After this she was asymptomatic until December 1978, when she complained of weight loss and muscle pains. This illness was diagnosed and treated as subacute bacterial endocarditis, although no organisms could be cultured from the blood. There was no clinical evidence

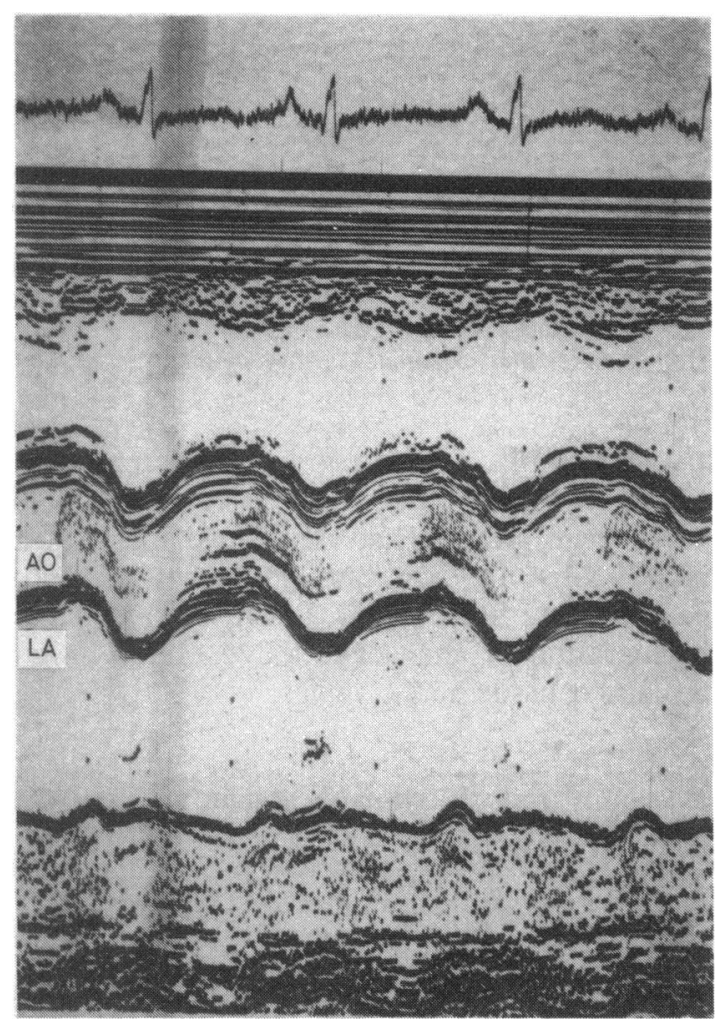

Fig. $2 M$ mode echocardiogram of the aortic valve showing fine fluttering echoes in diastole (case 2). AO, aorta; LA, left atrium.

of aortic incompetence before or during this illness, and she made a good recovery.

$M$ mode echocardiography performed during this illness showed a normally functioning bioprosthetic valve with no evidence of either aortic regurgitation or of vegetations (Fig. 3a).

In February 1980 an early diastolic murmur was noted for the first time. In February 1981 she complained of increasing dyspnoea. There was clinical evidence of pronounced aortic incompetence. M mode echocardiography showed notable diastolic fluttering of both leaflets of the mitral valve and of the septum. Mitral valve closure was normal in timing. The left ventricle was dilated and contracted poorly. There were fluttering echoes in systole in the aortic root (Fig. 3b). Diastolic vibrating echoes were seen in the aortic root and left ventricular outflow tract (Fig. 3c). Cross sectional echocardiography showed that the non-coronary cusp prolapsed into the left ventricular outflow tract.

At operation in November 1981 the Hancock valve was seen to have deficiencies in all three cusps, leaving a central orifice at all times (Fig. $3 d$ ). The non- 


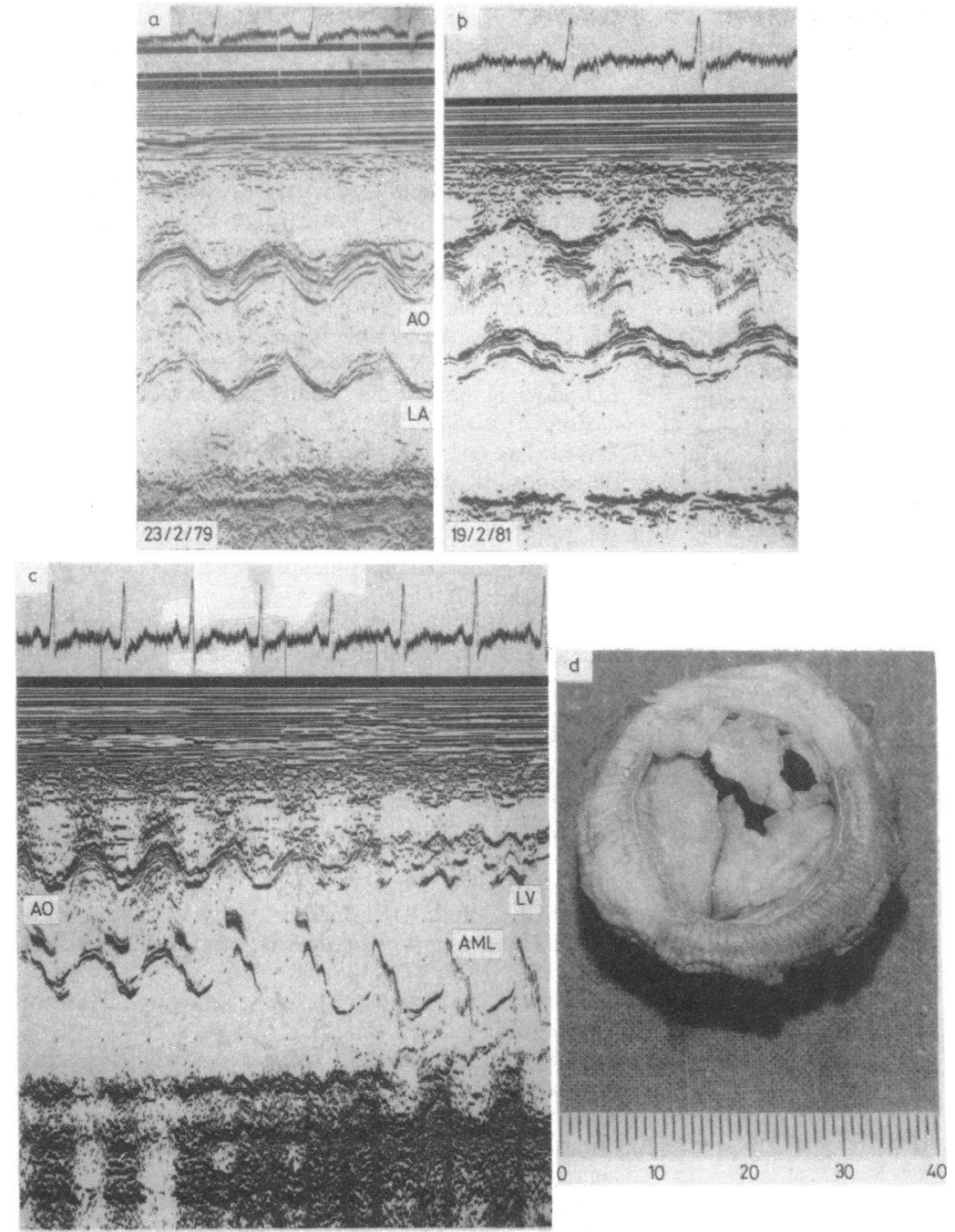

Fig. $3 M$ mode echocardiogram showing the Hancock xenograft in the aortic position (case 3) (a) on 23 February 1979 and (b) on 19 February 1981 when fluttering systolic echoes were evident. (c) $M$ mode echocardiographic scan from the aortic valve to the left ventricle showing fluttering diastolic echoes in the aortic root and in the left ventricular outflow tract (case 3). (d) Morphological appearance of Hancock xenograft showing deficiencies in all three cusps (case 3 ). $A O$, aorta; $A M L$, anterior mitral leaflet; $L V$, left ventricle.

coronary cusp was not supported and had fallen into the left ventricular outflow tract. No vegetations were seen. Histologically there was no evidence of an inflammatory response nor of bacterial infection.

\section{Discussion}

In each of the three patients with implanted tissue aortic valves in whom echocardiography showed a ruptured valve the diagnosis was confirmed at operation. There was a hole in one cusp of the homograft in one patient (case 2), deficiencies in all cusps of the xenografts with prolapse of a cusp in one (case 3 ) and of part of a cusp in one (case 1). In none was there any evidence of active infective endocarditis, although case 3 had had a febrile illness three years before.
Degeneration of the valve was thought to be spontaneous in all three.

Specific $M$ mode echocardiographic features were first described in association with rupture of the aortic valve by Lee $e t$ al who reported a band of high frequency echoes in early to mid diastole, with fine linear echoes during systole, in the aortic root in four patients in whom a rutpured aortic valve was subsequently confirmed. ${ }^{1}$

Since the initial description, similar echocardiographic appearances have been reported most often in association with active infective endocarditis affecting the aortic valve. Similar $M$ mode echocardiograms have been recorded in patients who had recovered from endocarditis one, two, four, and five years before $^{16-19}$ and in patients with a myxomatous or 
floppy valve. ${ }^{11}$

Wray suggested that irregular diastolic echoes in the left ventricular outflow tract, continuous with the aortic valve, were diagnostic of a flail cusp. ${ }^{23}$ Roy et al interpreted them as representing prolapse of a cusp or part of a cusp or a vegetation on the ventricular aspect of the valve. ${ }^{5}$ These echocardiographic appearances have not previously been described in association with implanted tissue valves.

Two of our patients had xenografts, one a Carpentier-Edwards and the other a Hancock valve. These glutaraldehyde fixed porcine valves occasionally lose their integrity. ${ }^{20} \mathrm{Cohn}$ et al reported dysfunction in seven of 528 such valves in the mitral or aortic area after six years. ${ }^{21}$ Calcification of the valves can occur, especially in children and young adults. ${ }^{22-24}$ Rupture of the cusps has been reported, Cohn et al having found two in 528.21 Ferrans et al reported six with perforations. ${ }^{23}$

Aortic homografts probably lose their integrity more often than do xenografts. Barratt-Boyes et al reported aortic incompetence in eight patients with aortic homografts who had died. ${ }^{25}$ There was rupture of a cusp in three. At reoperation for aortic incompetence rupture of a cusp was the cause in nine of 17 .

$M$ mode and cross sectional echocardiography may be used to detect disorganisation of the aortic valve. Abnormal fluttering echoes in systole and diastole in the aortic root suggest valve disruption. Vibrating diastolic echoes in the left ventricular outflow tract may be caused by prolapse of cusp tissue. When these features are recorded from an implanted tissue valve, either a homograft or a xenograft, they imply severe disruption, which may be due to spontaneous degeneration. This is likely to be progressive and may be an indication for aortic valve replacement.

\section{References}

1 Lee C-C, Das G, Weissler AM. Characteristic echocardiographic manifestations in ruptured aortic valve leaflet [Abstract]. Circulation 1974; 49 and 50 (suppl III): 144.

2 Wray TM. Echocardiographic manifestations of flail aortic valve leaflets in bacterial endocarditis. Circulation 1975; 51: 832-5.

3 Wray TM. The variable echocardiographic features in aortic valve endocarditis. Circulation 1975; 52: 658-63.

4 Gottlieb S, Khuddus SA, Balooki H, Dominguez AE, Myerburg RJ. Echocardiographic diagnosis of aortic valve vegetations in candida endocarditis. Circulation 1974; 50: 826-30.

5 Roy P, Tajik AJ, Giuliani ER, Schattenberg TT, Gau GT, Frye RL. Spectrum of echocardiographic findings in bacterial endocarditis. Circulation 1976; 53: 474-82.

6 Chandraratna PAN, Robinson MJ, Byrd C, Pitha JV. Significance of abnormal echoes in left ventricular outflow tract. Br Heart $\mathcal{F}$ 1977; 39: 381-9.
7 Rolston WA, Hirschfeld DS, Emilson BB, Cheitlin MD. Echocardiographic appearance of ruptured aortic cusp. Am $\mathcal{F}$ Med 1977; 62: 133-8.

8 Kleiner JP, Brundage BH, Ports TA, Thomas HM. Echocardiographic manifestation of flail right and noncoronary aortic valve leaflets. Chest 1978; 74: 301-3.

9 Ramirez J, Guardiola J, Flowers NC. Echocardiographic diagnosis of ruptured aortic valve leaflet in bacterial endocarditis. Circulation 1978; 57: 634-6.

10 Fox S, Kotler MN, Segal BL, Parry W. Echocardiographic diagnosis of acute aortic valve endocarditis and its complications. Arch Intern Med 1977; 137: 85-9.

11 Chandraratna PAN, Samet P, Robinson MJ, Byrd C. Echocardiography of the "floppy" aortic valve. Report of a case. Circulation 1975; 52: 959-62.

12 Das G, Lee CC, Weissler AM. Echocardiographic manifestations of ruptured aortic valvular leaflets in the absence of valvular vegetations. Chest 1977; 72: 464-8.

13 Whipple RL 3rd, Morris DC, Feiner JM, Merrill AJ, Miller JI. Echocardiographic manifestations of flail aortic valve leaflets. $\mathcal{F C U}$ 1977; 5: 417-22.

14 Estevez CM, Dillion JC, Walker PD, Feigenbaum H, Chang S. Echocardiographic manifestations of aortic cusp rupture in a myxomatous aortic valve. Chest 1976; 69: 685-7.

15 Krivokapich J, Child JS, Skorton DJ. Flail aortic valve leaflets: $M$-mode and two dimensional echocardiographic manifestations. Am Heart $\mathcal{F}$ 1980; 99: 425-37.

16 El Shahawny M, Graybeal R, Pepine CJ, Conti CR. Diagnosis of aortic valvular prolapse by echocardiography. Chest 1976; 69: 411-3.

17 Shiu MF, Coltart DJ, Braimbridge MV. Echocardiographic findings in prolapsed aortic cusp with vegetation. Br Heart f 1979; 41: 118-20.

18 Srivastava TN, Flowers NC. Echocardiographic features of flail aortic valve. Chest 1978; 73: 90-2.

19 Gaasch WH, Cleveland RJ. Echocardiographic examination in aortic regurgitation. Subaortic aneurysm and flail aortic leaflet. Chest 1976; 70: 771-3.

20 Spray TL, Roberts WC. Structural changes in porcine xenografts used as substitute cardiac valves. Gross and histologic observations in 51 glutaraldehyde-preserved Hancock valves in 41 patients. Am $\mathcal{F}$ Cardiol 1977; 40: 319-30.

21 Cohn LH, Koster JK, Mee RBB, Collins JJ Jr. Longterm follow-up of the Hancock bioprosthetic heart valve. A 6-year review. Circulation 1979; 60 (suppl 1): 87-92.

22 Thandroyen FT, Whitton IN, Pirie D, Rogers MA, Mitha AS. Severe calcification of glutaraldehydepreserved porcine xenografts in children. Am f. Cardiol 1980; 45: 690-6.

23 Ferrans VJ, Boyce SW, Billingham ME, Jones M, Ishihara T, Roberts WE. Calcific deposits in porcine bioprostheses: structure and pathogenesis. Am $\mathcal{F}$ Cardiol 1980; 46: 721-34.

24 Silver MM, Pollock J, Silver MD, Williams WG, Trusler GA. Calcification in porcine xenografts in children. $A m \mathcal{F}$ Cardiol 1980; 45: 685-9.

25 Barratt-Boyes BG, Roche AHG, Brandt PWT, Smith JC, Lowe JB. Aortic homograft valve replacement. A longterm follow-up of an initial series of 101 patients. Circulation 1969; 40: 763-75. 